\title{
Effect of Brassinosteroids on Germination and Seedling Growth of Radish (Raphanus sativus L.) under PEG-6000 Induced Water Stress
}

\author{
Kommavarapu Mahesh, Parshavaneni Balaraju, Bellamkonda Ramakrishna, Sadhu Seeta Ram Rao
}

Osmania University, Hyderabad, India.

Email: mahesh.kommavarapu2011@gmail.com

Received September $10^{\text {th }}, 2013$; revised October $16^{\text {th }}, 2013$; accepted November $3^{\text {rd }}, 2013$

Copyright (C) 2013 Kommavarapu Mahesh et al. This is an open access article distributed under the Creative Commons Attribution License, which permits unrestricted use, distribution, and reproduction in any medium, provided the original work is properly cited.

\begin{abstract}
Effect of 24-epibrassinolide and 28-homobrassinolide on the germination and seedling growth of radish (Raphanus sativus) subjected to water stress being imposed by $15 \%(\mathrm{w} / \mathrm{v})$ polyethylene glycol (equivalent to -2.95 bars of osmotic pressure) was studied. Brassinosteroids supplementation reduced the inhibitory effect of water stress on seed germination and seedling growth. The growth stimulation in radish seedlings by brassinosteroids under desiccation stress was associated with elevated levels of nucleic acids and soluble proteins and lowered activities of RNase. The mitigation of osmotic stress imposed by PEG was associated with increased scavenging of reactive oxygen species as reflected in elevated activities of superoxide dismutase, catalase and ascorbate peroxidase. Brassinosteroids also enhanced the accumulation of the osmolyte free proline in radish seedlings challenged with drought stress. The two brassinosteroids also maintained membrane integrity under water deficiency conditions as indicated by lowered lipid peroxidation reflecting in reduced MDA content. The results of present study demonstrate the protective role of brassinosteroids against PEG imposed water stress in radish seedlings.
\end{abstract}

Keywords: 24-Epibrassinolide; 28-Homobrassinolide; Antioxidative System; Malondialdehyde;

Polyethylene Glycol-6000; Radish; Water Stress

\section{Introduction}

Water stress is the most important abiotic stress limiting the plant growth. Water stress leads to a series of morphological, physiological and molecular changes which adversely affect plant growth. Drought stress is primarily manifested as osmotic stress resulting in the disruption of homeostasis and ion distribution in the cell [1]. Seed germination is the most critical stage in plant life cycle which is severely affected in water limiting conditions. Further, establishment of seedlings in dry environment is a major reason for seedling mortality. Phytohormones have been implicated in modulating the plant response to desiccation stress. Brassinosteroids (BRs) are a new group of phytohormones which regulate broad spectrum of physiological processes including seed germination, plant growth, vascular differentiation and photomorphogenetic process [2,3]. One of the most promising roles of BRs is their ability to confer resistance to wide array of abiotic stresses $[4,5]$. The osmotic solution is used to impose water stress reproducibly under in vitro conditions. Polyethylene glycol (PEG) widely used to induce water stress, is a non-ionic water polymer which is not expected to penetrate into plant tissue rapidly [6]. As PEG does not enter the apoplast, water is withdrawn from the cell including cell wall and thus PEG solutions mimic dry soils more closely than solutions of low-MR osmotica which infiltrate the cell wall with solution [7].

In the present study, the impact of brassinosteroids on seed germination and seedling growth of Raphanus sativus L. under water stress as imposed by PEG is being investigated.

\section{Materials and Methods}

24-epibrassinolide (EBL) and 28-homobrassinolide (HBL) were purchased from CID tech research Inc, Mississauga, Ontario, Canada. Seeds of radish (Raphanus sativus L.) Pusachekthi varieties were obtained from National Seed Corporation, Hyderabad. After preliminary 
experiments employing a range of concentrations of polyethylene glycol (PEG 6000), a concentration of $15 \%$ was selected as the drought stress concentration. The osmotic potential of $15 \%$ aqueous solution of PEG is -2.95 bars at $25^{\circ} \mathrm{C}[8]$.

Seeds were surface sterilized with $0.5 \%(\mathrm{v} / \mathrm{v})$ sodium hypochlorite solution from commercially available $4 \%$ $\mathrm{NaClO}$ and washed thoroughly with several changes of sterile distilled water. They were soaked for $24 \mathrm{~h}$ either in 1) Distilled water (control) 2) $0.5,1.0$ and $2.0 \mu \mathrm{M}$ concentrations of EBL and HBL 3) $15 \%$ Polyethylene glycol (stressed control) 4) 15\% Polyethylene glycol supplemented with brassinosteroids. The two brassinosteroids (EBL and HBL) were employed at 3 concentration levels viz., $0.5 \mu \mathrm{M}, 1.0 \mu \mathrm{M}$ and $2.0 \mu \mathrm{M}$. 20 seeds for each treatment were distributed in separate petri plates $(15 \mathrm{~cm}$ diameter) provided with whatman No. 1 filter papers. The seeds were allowed to germinate in the dark at $25 \pm 1{ }^{\circ} \mathrm{C}$. The number of seeds germinated was recorded at the end of $24 \mathrm{~h}$ and $36 \mathrm{~h}$ under safe green light. After $72 \mathrm{~h}, 5$ seedlings were retained in each plate and 5 $\mathrm{ml}$ test solution was added. On the seventh day seedling growth in terms of length, fresh and dry weight was recorded. For recording dry weight seedlings were dried at $110^{\circ} \mathrm{C}$ for $24 \mathrm{~h}$ in hot air oven.

On the seventh day fresh seedlings material $(200 \mathrm{mg})$ was homogenized with $70 \%(\mathrm{v} / \mathrm{v})$ ethyl alcohol and stored in deep freezer. The alcoholic homogenate was used for nucleic acid and soluble protein estimation.

\section{Nucleic Acids}

DNA and RNA fractions in the ethyl alcohol homogenate were separated by the method of Ogur and Rosen [9]. DNA was estimated by the procedure of Burton [10] employing diphenylamine reagent and RNA was quantified by the method of Schneider [11] using Orcinol reagent.

\section{Soluble Proteins}

Soluble proteins in alcohol homogenate (extract in case of enzyme assay) were precipitated by using $20 \%$ (w/v) trichloroacetic acid. The precipitate was dissolved in 5 $\mathrm{ml}$ of $1 \%(\mathrm{w} / \mathrm{v})$ sodium hydroxide and was centrifuged at $4000 \mathrm{rpm}$ for $10 \mathrm{~min}$. The supernatant was used for estimation of proteins by Lowry et al. [12] method.

\section{Free Proline}

The amount of proline content was estimated as described by Bates and others [13]. Seedling material $(0.5 \mathrm{~g})$ was homogenized with $10 \mathrm{ml}$ of $3 \%(\mathrm{w} / \mathrm{v})$ sulfosalicylic acid and the homogenate was filtered through whatman No. 2 filter paper. The supernatant was taken for proline estimation. The reaction mixture was composed of $2 \mathrm{ml}$ of plant extract, $2 \mathrm{ml}$ of acid ninhydrin reagent and $2 \mathrm{ml}$ of glacial acetic acid and heated in a boiling water bath for one $\mathrm{h}$. The reaction was terminated in an ice bath followed by addition of $4 \mathrm{ml}$ of toluene. The contents were shaken vigorously and then allowed to separate into phases. The chromophase containing upper toluene phase was carefully taken out with the help of a pipette and the absorbance was taken at $520 \mathrm{~nm}$. The amount of proline present was quantified with the help of proline standard graph.

\section{Lipid Peroxidation}

Lipid peroxidation was determined by estimating the malondialdehyde (MDA) content following the method of Heath and Packer [14]. Seedlings (1.0 g) were homogenized with $3 \mathrm{ml}$ of $0.5 \%$ thiobarbituric acid (TBA) in $20 \%$ trichloroacetic acid $(\mathrm{v} / \mathrm{v})$. The homogenate was incubated at $95^{\circ} \mathrm{C}$ for $30 \mathrm{~min}$ and the reaction was stopped in ice. The samples were centrifuged at 10,000 $\times$ $\mathrm{g}$ for $5 \mathrm{~min}$ the absorbance of the resulting supernatant was recorded at $532 \mathrm{~nm}$ and $600 \mathrm{~nm}$. The non-specific absorbance at $600 \mathrm{~nm}$ was subtracted from the $532 \mathrm{~nm}$ absorbance. The absorbance coefficient of MDA was calculated by using the extinction coefficient of $155 \mathrm{mM}^{-1}$ $\mathrm{cm}^{-1}$.

\section{Antioxidant Enzymes}

The fresh seedling material $(200 \mathrm{mg})$ was homogenized with sodium phosphate buffer at $\mathrm{pH} 7.0$ for CAT, POD, and APX and at $\mathrm{pH} 7.8$ for SOD activities. The supernatant was used to measure the activity of the enzymes and the protein content in the supernatant was determined according to Lowry et al.

Catalase (CAT, EC; 1.11.1.6) activity was assayed by the method of Barber [15]. Enzyme extract $(0.5 \mathrm{ml})$ was added to $2.0 \mathrm{ml}$ of hydrogen peroxide and $3.5 \mathrm{ml}$ of phosphate buffer ( $\mathrm{pH}$ 7.0). The reaction was stopped by adding $10.0 \mathrm{ml}$ of $2 \%(\mathrm{v} / \mathrm{v})$ concentrated sulphuric acid, and the residual hydrogen peroxide was titrated against $0.01 \mathrm{M} \mathrm{KMnO}_{4}$ until a faint purple color persisted for at least $15 \mathrm{sec}$. The activity of the enzyme was expressed as enzyme units.

Peroxidase (POD, EC; 1.11.1.7) activity was assayed adopting the method of Kar and Mishra [16]. To $0.5 \mathrm{ml}$ of enzyme extract, $2.5 \mathrm{ml}$ of $0.1 \mathrm{M}$ phosphate buffer $(\mathrm{pH}$ 7.0), $1.0 \mathrm{ml}$ of $0.01 \mathrm{M}$ pyrogallol and $1.0 \mathrm{ml}$ of $0.005 \mathrm{M}$ $\mathrm{H}_{2} \mathrm{O}_{2}$ were added. After incubation, the reaction was stopped by adding $1.0 \mathrm{ml}$ of $2.5 \mathrm{~N} \mathrm{H}_{2} \mathrm{SO}_{4}$. The amount of purpurogallin formed was estimated by measuring the absorbance at $420 \mathrm{~nm}$. The enzyme activity was expressed in absorbance units.

Ascorbate peroxidase (APX, EC; 1.11.1.11) activity 
was measured according to the Nakano and Asada [17]. The reaction mixture contained $50 \mathrm{mM}$ phosphate buffer (pH 7.0), $0.2 \mathrm{mM}$ EDTA, $0.5 \mathrm{mM}$ ascorbic acid, $250 \mathrm{mM}$ $\mathrm{H}_{2} \mathrm{O}_{2}$ and enzyme extract. The activity of APX was measured spectrophotometrically by measuring the rate of ascorbate oxidation at $290 \mathrm{~nm}$ for $1 \mathrm{~min}$. The amount of ascorbate was calculated from the extinction coefficient of $2.6 \mathrm{mM}^{-1} \mathrm{~cm}^{-1}$.

Superoxide dismutase (SOD, EC; 1.15 .1 .1 ) activity was determined based on inhibition of the photochemical reduction of nitrobluetetrazolium (NBT) [18]. The reaction mixture contained $50 \mathrm{mM}$ sodium phosphate buffer (pH 7.8), $1.5 \mathrm{ml}$ methionine, $1 \mathrm{ml}$ of NBT, $0.75 \mathrm{ml}$ triton-X-100, $2 \mathrm{mM}$ EDTA, $10 \mu \mathrm{L}$ of riboflavin and $50 \mu \mathrm{g}$ of protein. One unit of activity is the amount of protein required to inhibit $50 \%$ initial reduction of NBT under light.

Ribonuclease (E.C; 3.1.27.5) enzyme was extracted and assayed by adopting the method of Corbishley et al. [19] $200 \mathrm{mg}$ of seedling material was ground in a chilled mortar with $10 \mathrm{ml}$ of $0.05 \mathrm{M}$ potassium acetate buffer (pH 6.5). The homogenate was centrifuged at $4^{\circ} \mathrm{C}$ for 20 $\mathrm{min}$ at $20,000 \mathrm{rpm}$. The assay mixture contained $5 \mathrm{ml}$ of $100 \mu \mathrm{g}$ ml-yeast RNA in $0.05 \mathrm{M}$ potassium acetate buffer ( $\mathrm{pH}$ 6.8) and $1 \mathrm{ml}$ of enzyme extract and this was incubated for $2 \mathrm{~h}$ at $37^{\circ} \mathrm{C}$. At the end of incubation period, the undigested nucleic acid was precipitated with $4 \mathrm{ml}$ of chilled perchloric acid ethanol mixture (5\% of perchloric acid in absolute ethanol). The contents were chilled for one $\mathrm{h}$ and centrifuged at $4^{\circ} \mathrm{C}$. The supernatant taken as the enzyme extract was diluted to $20 \mathrm{ml}$ with buffer and optical density was recorded at $260 \mathrm{~nm}$ against blank at zero time. Enzyme activity was expressed in absorbance units.

\section{Statistical Analysis}

The experiments were repeated twice with adequate replicates to obtain sufficient plant material for analysis. However values of 5 replicates of each parameters recorded were subjected to statistical scrutiny. Standard error (SE) of the mean values $(n=5)$ in figures of sample variability was given. The data was analyzed by One way analysis of variance (ANOVAs), followed by Post Hoc Test (Multiple Comparison). The differences were considered significant if $P$ was at least $\leq 0.05$. SPSS version 13.0 software is used for all statically analysis.

\section{Results and Discussion}

Water stress resulted in delayed and decreased seed germination (Figure 1). However supplementation of BRs to water stress treatments improved the seed germination. EBL and HBL at $2 \mu \mathrm{M}$ concentration completely removed the inhibitory impact of water stress imposed by PEG on seed germination. Brassinosteroids (EBL and HBL) alone treatments also caused good increase in seed germination over untreated controls. It has been reported that 24-epibrassinolide significantly shortened the dormant period of embryos and increased germination percentage of cherry plum and sloe embryos [20]. Brassinosteroids promoted seed germination by enhancing the growth potential of the embryo of tobacco seedlings [21]. Brassinosteroids also overcome the inhibition of germination by abscisic acid in Arabidopsis [22]. Brassinosteroids removed the inhibitory effect of salt on the seed germination of Eucalyptus camaldulensis [23] and rice

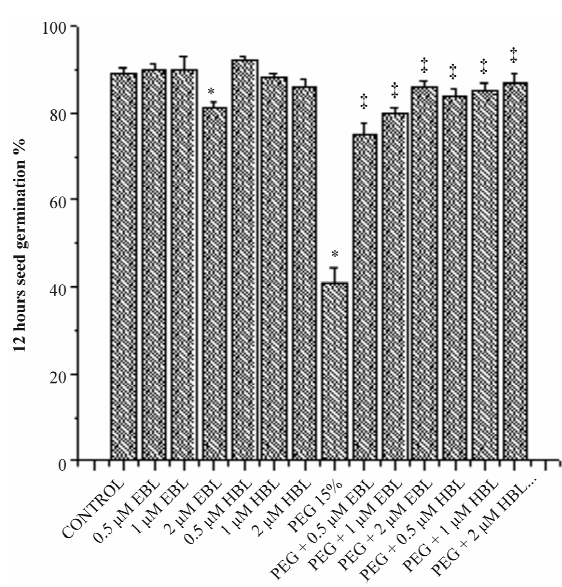

(a)

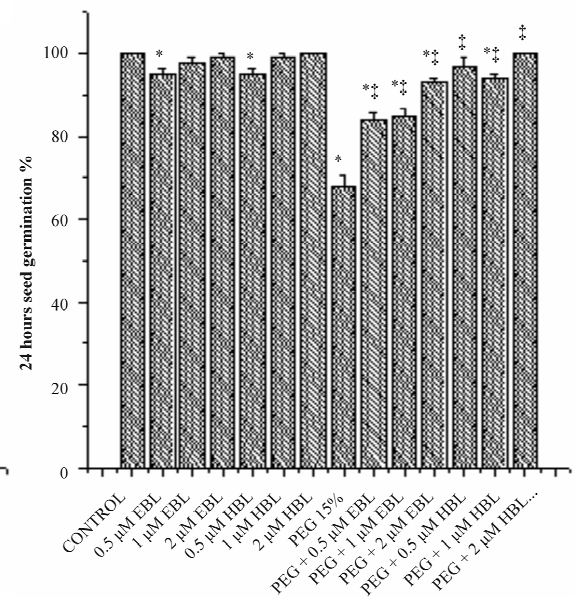

(b)

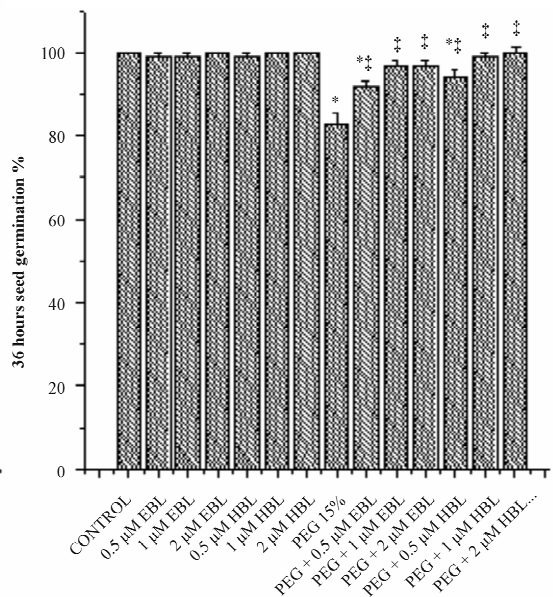

(c)

Figure 1. Effect of BRs on $12 \mathrm{~h}$ seed germination (a), $24 \mathrm{~h}$ seed germination (b) and $36 \mathrm{~h}$ seed germination (c) of radish seedlings grown under PEG imposed water stress. $(\mathrm{OP}=-2.95$ bars). Vertical bars represent the mean $\pm \mathrm{SE}$ of five replicates. Star and double dagger denote that mean values are significantly different from control and PEG imposed water stress $(O P=$ -2.95 bars) treatments, respectively at $P \leq 0.05$ according to Post Hoc Test. 
[24]. Brassinosteroids were also found to remove the toxicity of cadmium on seed germination of radish [25].

Under desiccation stress, the growth of seedlings was found severely impaired as reflected in reduced length, fresh weight and dry weight (Figures 2(a)-(c)). The growth of juvenile seedlings under stress is highly sensitive and prone to damage due to water stress. Seed germination and early seedling development are the initial handicaps for establishment of plants in dry terrain. However both the BRs significantly increased the seedling growth of radish under water stress conditions. Brassinosteroid alone treatments also caused good improvement in seedling growth. The supplementation of BRs to water stress treatments not only rescued the seedling growth, but also further improved. The results of present study clearly demonstrated the alleviation of water stress by BRs. Further, the ameliorating capability of the BRs was found to be dose dependent. At $2 \mu \mathrm{M}$ concentration, BRs completely eliminated the impact of PEG on radish seedlings growth which was reflected in all the vegetative parameters recorded (Figure 2). The growth promoting effects of BRs on seedlings under stress conditions might be attributed to their involvement in cell elongation and cell cycle progression [26] as well as regulation of genes encoding xyloglucan endotransglucosylase/hydrolases (XTHs), expansions, glucanases, sucrose synthase and cellulose synthase or by activating the H+-ATPase activity [27].

The growth reduction under water stress was manifested in reduced content of nucleic acids (Figure 3).

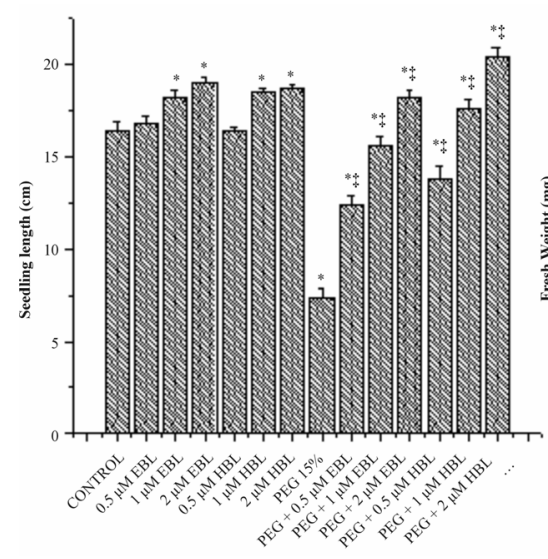

(a)

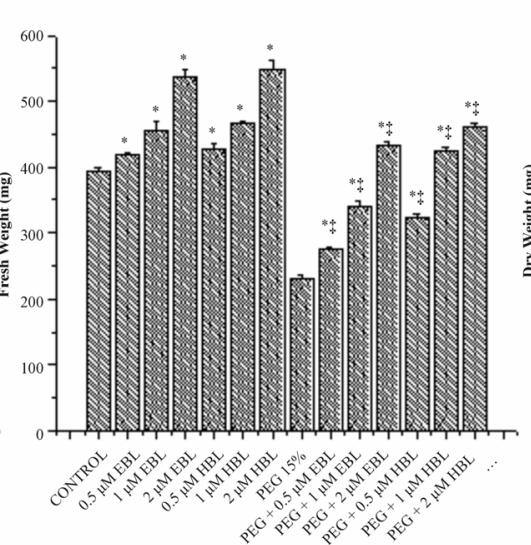

(b)

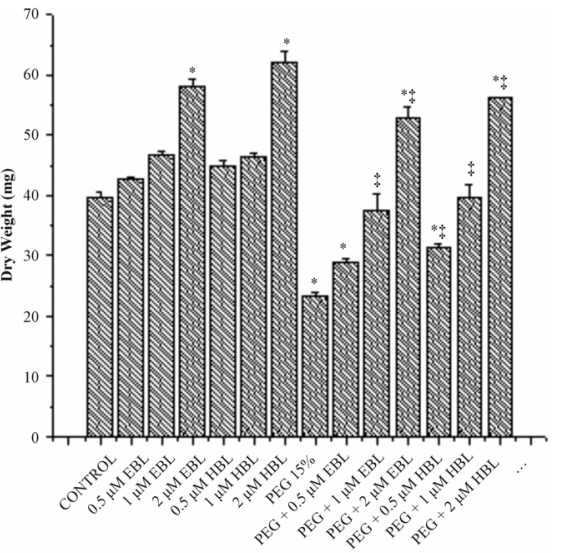

(c)

Figure 2. Effect of BRs on seedling length (a), fresh weight (b) and dry weight (c) of radish seedlings grown under PEG imposed water stress $(\mathrm{OP}=-\mathbf{2 . 9 5} \mathrm{bars})$. Vertical bars represent the mean $\pm \mathrm{SE}$ of five replicates. Star and double dagger denote that mean values are significantly different from control and PEG imposed water stress $(O P=-2.95$ bars $)$ treatments, respectively at $P \leq 0.05$ according to Post Hoc Test.

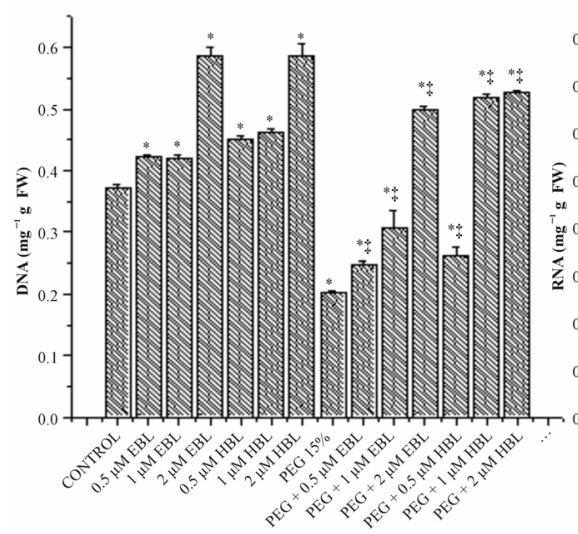

(a)

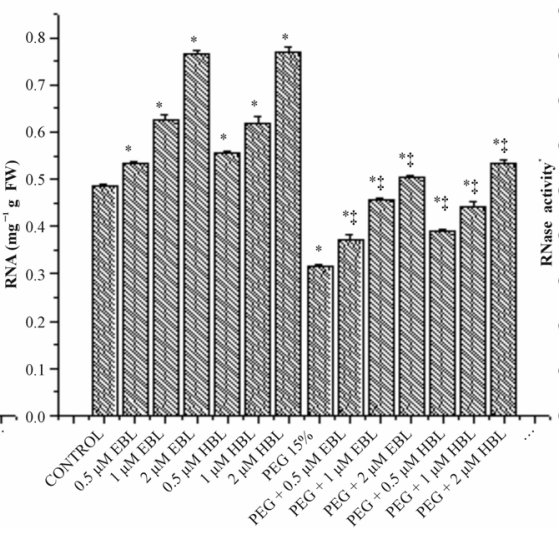

(b)

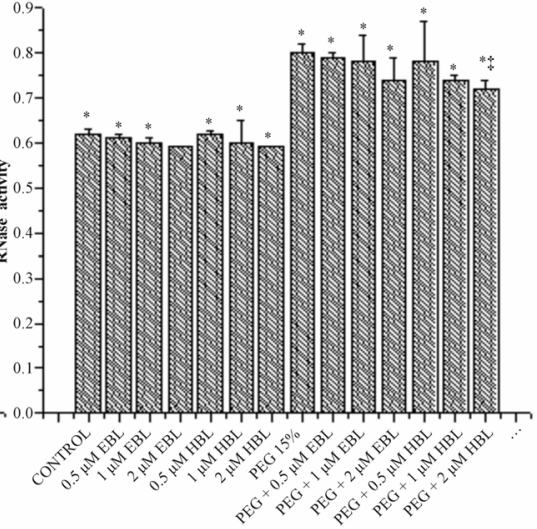

(c)

Figure 3. Effect of BRs on the levels of DNA (a), RNA (b) and RNase (c) activity of radish seedlings grown under PEG imposed water stress $(\mathrm{OP}=-\mathbf{2 . 9 5}$ bars). Vertical bars represent the mean $\pm \mathrm{SE}$ of five replicates. Star and double dagger denote that mean values are significantly different from control and PEG imposed water stress $(\mathrm{OP}=-2.95$ bars $)$ treatments, respectively at $P \leq 0.05$ according to Post Hoc Test. 
The decline in the levels of nucleic acids was found negated by the exogenous application of BRs. Even in BRs alone treatments also, the levels of nucleic acids were found higher than the untreated and unstressed controls. The growth promotion in radish seedlings by BRs in unstressed and water stressed conditions was found associated with enhanced levels of DNA and RNA (Figures 3(a) and (b)) and lowered RNase activity (Figure 3(c)). It has been suggested by Key [28] that phytohormones regulate the growth by affecting nucleic acid synthesis. The results obtained in the present study with BRs are in conformity with the observations made by Key. The increase in the levels of nucleic acids might be due to enhanced synthesis and reduced degradation. Mung bean seedlings, when treated with 24-epibrassinolide, are reported to exhibit elevated activity of RNA polymerase and lowered activity of RNase and DNase [29]. Similarly, BRs application markedly increased the DNA and RNA content in $3 \mathrm{w}$ old maize plants under salinity stress [30]. The ameliorative influence of BRs on salinity stress induced growth inhibition in rice plants was linked to elevated levels of nucleic acids [31].

In radish seedlings under drought stress, there was remarkable decline in soluble proteins. Supplementation of BRs resulted in improvement in soluble protein content in radish seedlings growing under water stress. Brassinosteroids alone treatments also cause enhancement in soluble protein levels (Figure 4(a)). Sasse, [32] suggested that BRs can stimulate the synthesis of particular proteins associated with growth. Supplementing the culture media with 24-epibrassinolide increased cell division rate and soluble protein content in Chinese cabbage protoplasts [33]. Sairam [34] also obtained enhanced protein levels in wheat plants by 28 -homobrassinolide under moisture stress. Similarly, the alleviating influence of BRs on salinity stress induced inhibition of growth in rice was found associated with elevated levels of proteins [35].

Phytotoxicity from water stress is closely related to the production of reactive oxygen species (ROS) in plants. An imbalance between ROS production and ROS scavenging leads to oxidative burst. ROS can react with lipids, DNA and proteins, and causes membrane damage and enzyme inactivation resulting in inhibition of plant growth [36]. In order to scavenge ROS and to counter oxidative stress, plants evolved an efficient antioxidant defense system. SOD constitutes the first line of defense against ROS in plants, and this enzyme catalyzes the detoxification of $\mathrm{O}_{2}^{-}$to $\mathrm{H}_{2} \mathrm{O}_{2}$ and $\mathrm{O}_{2}$ [37]. SODs are the most efficient scavengers of the superoxide anion [38]. In the present study, a significant increase in SOD activity was observed in water stressed radish seedlings, suggesting an important role in removing $\mathrm{O}_{2}^{-}$, induced by water stress (Figure 5(c)). Exogenous application of both BRs further enhanced the SOD activity under both normal and water stressed seedlings reflecting enhanced $\mathrm{O}_{2}^{-}$scavenging.

Water stress induced by PEG led to increasing in the activity of CAT (Figure 5(a)). Supplementation of BRs to water stress resulted in further elevation of CAT activity. The decomposition of $\mathrm{O}_{2}^{-}$(produced under water stress) always accompanied by production of $\mathrm{H}_{2} \mathrm{O}_{2}$ which diffuses across the plasma membrane and is toxic as it acts as both an antioxidant as well as reductant [39]. Catalase further breaks down the $\mathrm{H}_{2} \mathrm{O}_{2}$ to water and oxygen [40]. Enhanced CAT activity in radish seedlings treated with BRs under water stress might have resulted in the oxidation of harmful substances, leading to resto-

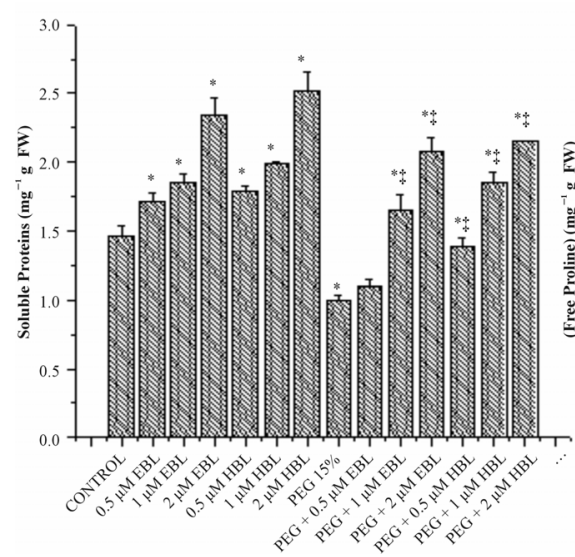

(a)

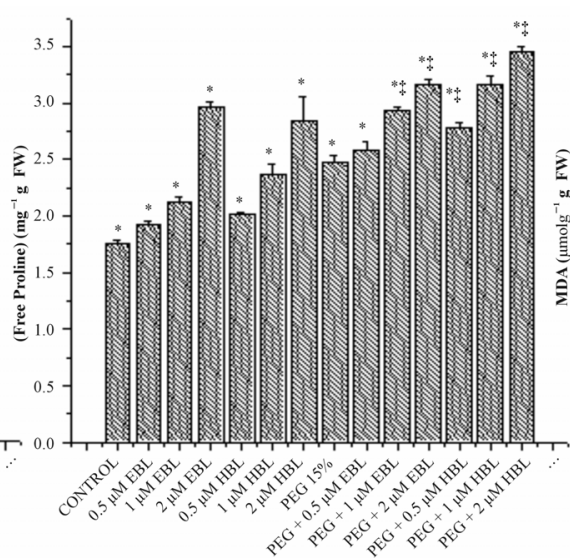

(b)

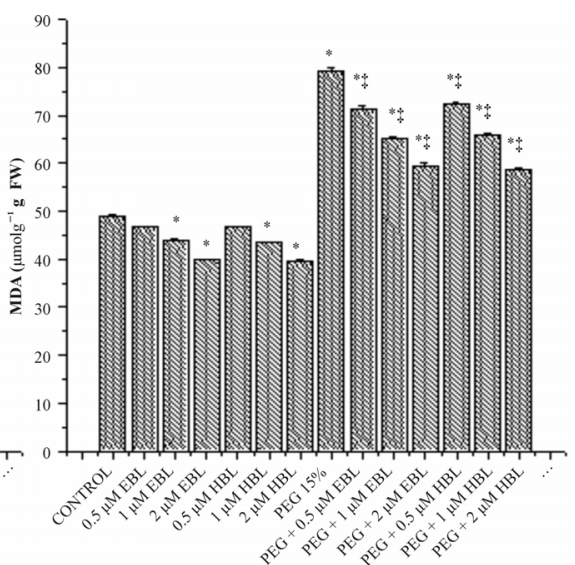

(c)

Figure 4. Effect of BRs on soluble proteins (a) free proline (b) and MDA (c) of radish seedlings grown under PEG 15\% stress. Vertical bars represent the mean $\pm \mathrm{SE}$ of five replicates. Star and double dagger denote that mean values are significantly different from control and PEG imposed water stress $(\mathrm{OP}=-\mathbf{2 . 9 5}$ bars $)$ treatments, respectively at $\mathrm{P} \leq 0.05$ according to $\mathrm{Post}$ Hoc Test. 


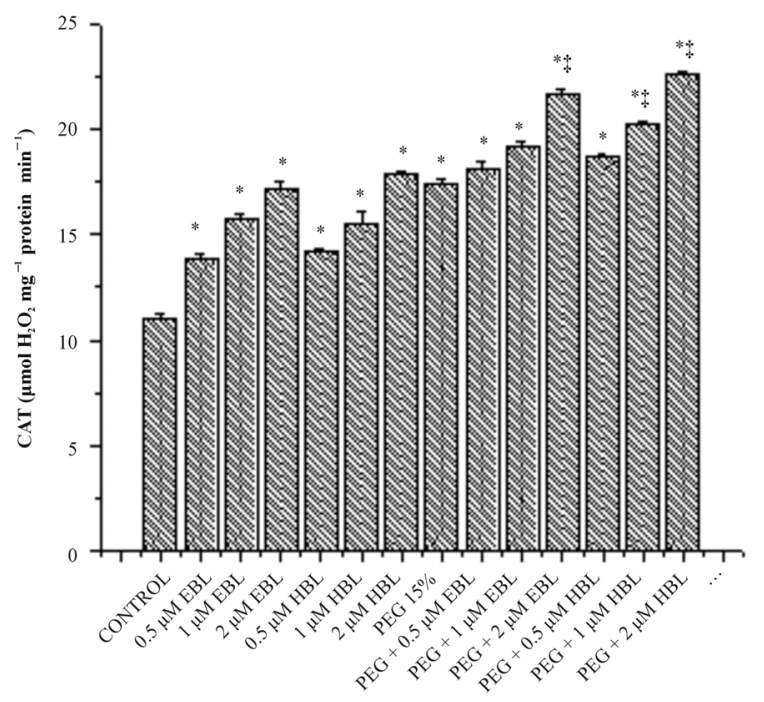

(a)

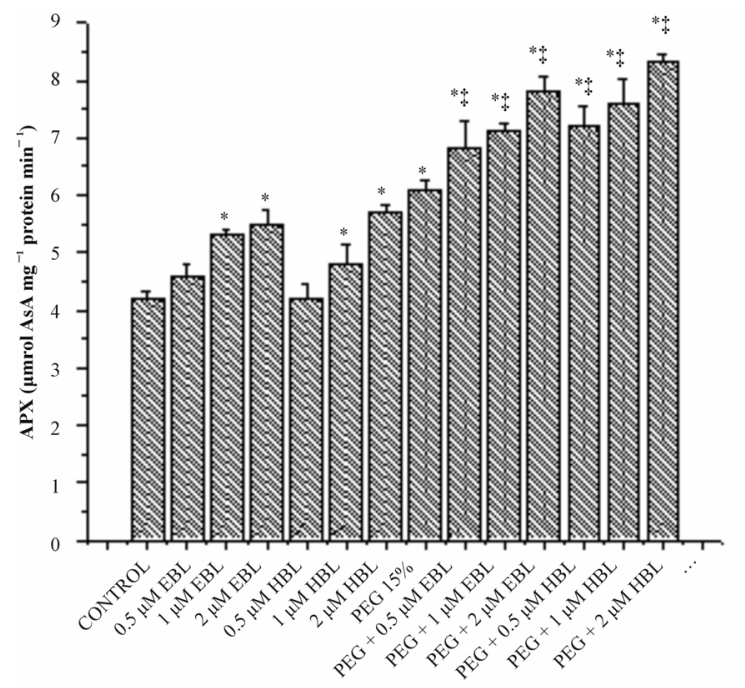

(c)

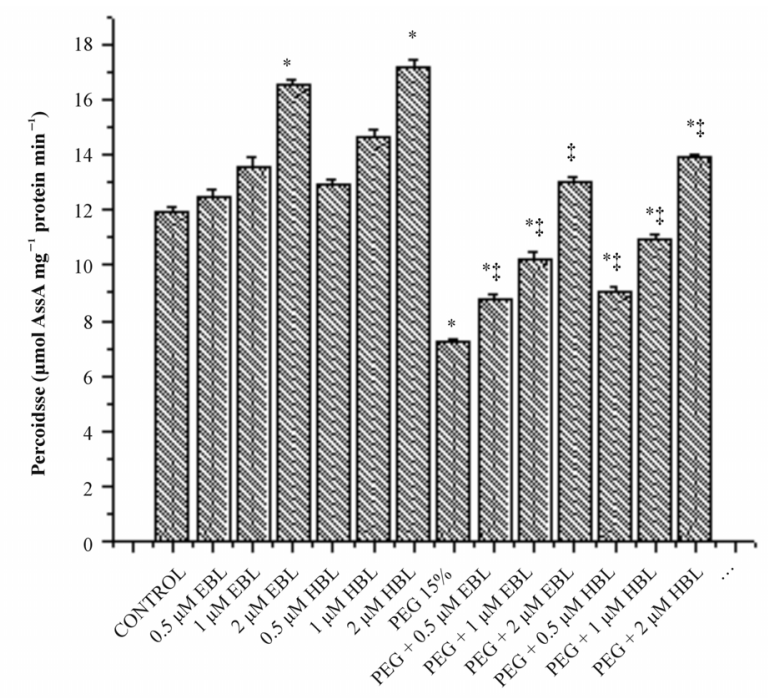

(b)

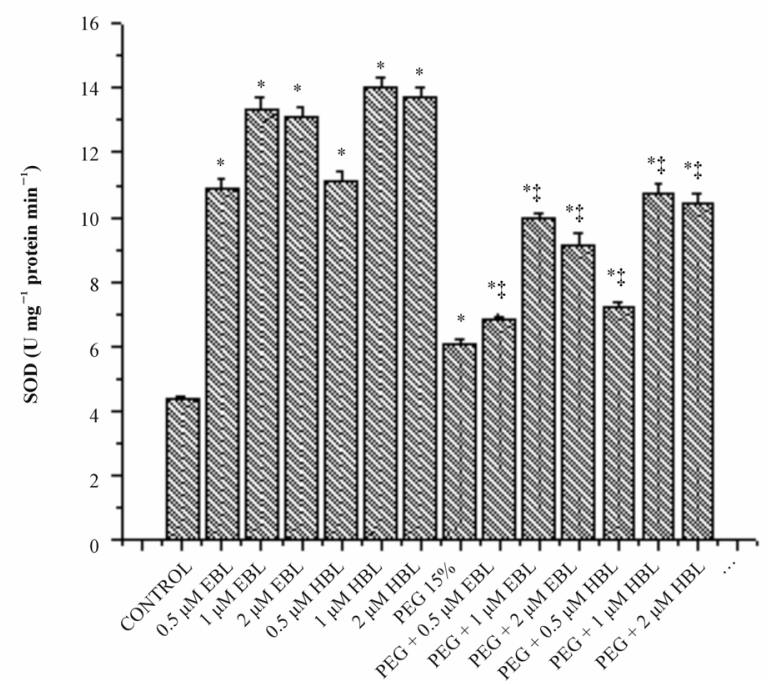

(d)

Figure 5. Effect of BRs on the activities of CAT (a), POD (b), SOD (c) and APX (d) in radish seedlings grown under PEGS imposed water stress $(\mathrm{OP}=-\mathbf{2 . 9 5}$ bars $)$ stress. Vertical bars represent the mean $\pm \mathrm{SE}$ of five replicates. Star and double dagger denote that mean values are significantly different from control and $P E G 15 \%$ treatments, respectively at $P \leq 0.05$ according to Post Hoc Test.

ration of growth. Cao et al. [41] suggested that BRs enhance the oxidative stress resistance in Arabidopsis by increasing the transcript levels of defense gene catalase. However BRs alone as well as supplementation of BRs to water stressed seedlings increased the activities of employing the protective role of BRs through efficient scavenging of ROS. These results agree well with Behnamnia et al. [42], who reported that 24-epibrassinolide increased the CAT activity under drought stress in $L y$ copersicon esculentum.

Peroxidase activity was decreased, in water stressed seedlings compared with the control. With BRs supplementation to water stressed seedlings, peroxidase activity enhanced significantly. BRs alone treatments increased POD activity reporting maximum at $2 \mu \mathrm{M}$ concentration for both the steroids (Figure 5(b)). Similar increase in POD activity was observed in soybean under water deficient due to BRs application [43]. Ascorbate peroxidase which uses reduced ascorbate as a reductant in the first step of ascorbate-glutahione cycle is recognized as the most important peroxidase in $\mathrm{H}_{2} \mathrm{O}_{2}$ detoxification [44]. Under water stress, increased activity of APX was observed reflecting elevated $\mathrm{H}_{2} \mathrm{O}_{2}$ detoxification (Figure 5(d)). Application of BRs to water stressed seedlings further enhanced the APX activity, indicating the efficient scavenging of $\mathrm{H}_{2} \mathrm{O}_{2}$ thereby preventing the $\mathrm{H}_{2} \mathrm{O}_{2}$ - 
mediated cell damage. Similarly, Bajguz [45] observed that exogenous application of brassinolide increased the activity of APX in Chlorella cultures under heavy metal stress.

In water stressed seedlings there was a marked increase in MDA content (Figure 4(c)) reflecting lipid peroxidation and loss of membrane integrity. Water stress caused severe lipid peroxidation due to the removal of hydrogen by ROS from unsaturated fatty acids leading to lipid radical formation which leads to formation of alkenes and lipid and aldehydes which destroy the lipid structure. Feeding BRs to water stressed seedlings resulted in decline in lipid peroxidation as indicated by lower MDA content. The decrease in the levels of MDA, the key indicator of stress indication demonstrates the efficient stress management by BRs.

Results of the present study reported that PEG induced significant water deficient in radish seedlings, and no other toxicities were observed at seedling level following the addition of PEG-6000. Both the BRs employed in the study reversed the inhibitory effect of water stress on seed germination and all the above reported parameters. BRs alone treatments are analysed promising results that are substantial improvement rather than control treatment. However application of BRs on PEG treated seedlings plunging the water deficient and the seedlings reached to near control treated plants.

Osmolytes play significant protective role in plant responses to water stress and resistance. Under water stress, proline concentration can reach up to $80 \%$ of the total amino acid pool. In the present study, osmotic stress imposed by PEG caused substantial increment free proline levels and furtherance of proline content was found in radish seedlings exposed to desiccation stress (Figure 4(b)). The biochemical defense system against abiotic stress involves the amino acid proline (an osmolyte) which acts as cellular protectors largely accumulated in several plant species in response to abiotic stress, and scavenge ROS [46]. Farooq et al. [47] also observed that application of BRs increased the free proline levels in rice under drought stress. Alleviation of $\mathrm{Zn}$ toxicity by 24-epibrassinolide was also found to be watered with accumulation of proline in radish seedlings [48]. The findings of present investigation suggest that BRs are playing a positive role in combating the PEG-induced drought stress by enhancing the levels of metabolites and the activities ROS scavenging enzymes thereby keeping ROS levels under control and maintaining cellular redox status.

\section{Acknowledgement}

The financial support under OU-DST Promotion of University Research and Scientific Excellence Programme sponsored by Department of Science and Technology New Delhi, India is gratefully acknowledged.

\section{REFERENCES}

[1] W. Wang, B. Vinocur and A. Altman, "Plant Responses to Drought Salinity and Extreme Temperatures towards Genetic Engineering for Stress Tolerance," Planta, Vol. 218, No. 1, 2003, pp. 1-14. http://dx.doi.org/10.1007/s00425-003-1105-5

[2] S. S. R. Rao, B. V. Vardhini, E. Sujatha and S. Anuradha, "Brassinosteroids-New class of Phytohormones," Current Science, Vol. 82, No. 10, 2002, pp. 1239-1245.

[3] J. M. Sasse, "Physiological Actions of Brassinosteroids: An Update," Journal of Plant Growth Regulation, Vol. 22, No. 4, 2003, pp. 276-288. http://dx.doi.org/10.1007/s00344-003-0062-3

[4] A. Bajguz and S. Hayat, "Effects of Brassinosteroids on the Plant Responses to Stresses," Plant Physiology and Biochemistry, Vol. 47, No. 1, 2009, pp. 1-8. http://dx.doi.org/10.1016/i.plaphy.2008.10.002

[5] B. V. Vardhini, S. Anuradha, E. Sujatha and S. S. R. Rao, "Role of Brassinosteroids in Alleviating Various Abiotic and Biotic Stresses-A Review," In: N. A. Anjum, Ed., Plant Nutrition and Abiotic Stress Tolerance I, Plant Stress 4 (Special Issue 1), Global Science Books, Ikenobe, pp. 56-61.

[6] T. K. Macar, O. Turan and Y. Ekmekcd, "Effects of Water Deficit Induced by PEG and $\mathrm{NaCl}$ on Chickpea (Cicer arietinum) Cultivars and Lines at Early Seedling Stages," Gazi University Journal of Science, Vol. 22, No. 1, 2009, pp. 5-14. http://dx.doi.org/10.1104/pp.116.4.1403

[7] P. E. Verslues, E. S. Ober, R. E. Sharp, "Root Growth and Oxygen Relations at Low Water Potentials, Impact of Oxygen Availability in polyethylene Glycol Solutions," Plant Physiology, Vol. 116, No. 4, 1998, pp. 1403-1412.

[8] E. Burlyn, M. Michel and R. Kaufmann, "The Osmotic Potential of Polyethylene Glycol 6000," Plant Physiology, Vol. 51, No. 5, 1973, pp. 914-916. http://dx.doi.org/10.1104/pp.51.5.914

[9] M. Ogur and G. Rosen, "The Extraction and Estimation of Deoxypentose Nucleic Acid and Pentose Nucleic Acids," Archive Biochemistry Biophysics, Vol. 24, 1950, pp. 262276.

[10] K. Burton, "Determination of DNA Concentration with Diphenyl Amine," In: L. Grossman and M. Meidave, Eds., Methods in Enzymology, Academic Press, New York, 1968, p. 163.

[11] W. C. Schneider, "Determination of Nucleic Acids in Tissues by Pentose Analysis," In: S. P. Colowick and W. O. Kaplan, Eds., Methods in Enzymology, Academic Press, New York, 1957, p. 680.

[12] O. H. Lowry, N. J. Rosebrough, A. L. Farr and R. J. Randall, "Protein Measurement with the Folin Phenol Reagent," Journal of Biological Chemistry, Vol. 193, No. 1, 1951, pp. 265-275.

[13] L. Bates, R. P. Waldren and I. D. Teare, "Rapid Determi- 
nation of Free Proline for Water-Stress Studies," Plant and Soil, Vol. 39, No. 1, 1973, pp. 205-207. http://dx.doi.org/10.1007/BF00018060

[14] R. L. Heath and L. Packer, "Photo Peroxidation in Isolated Chloroplasts 1 Kinetics and Stoichiometry of Fatty Acid Peroxidation," Archives of Biochemistry and Biophysics, Vol. 125, No. 1, 1968, pp. 189-198. http://dx.doi.org/10.1016/0003-9861(68)90654-1

[15] J. M. Barber, "Catalase and Peroxidase in Primary Leaves during Development and Senescence," Zentrum für Molekularbiologie der Pflanzen, Vol. 97, 1980, pp. 135-144.

[16] M. Kar and D. Mishra, "Catalase Peroxidase and Polyphenol Oxidase Activities during Rice Leaf Senescence," Plant Physiology, Vol. 57, No. 2, 1976, pp. 315-319. http://dx.doi.org/10.1104/pp.57.2.315

[17] Y. Nakano and K. Asada, "Hydrogen Peroxide Is Scavenged by Ascorbate Specific Peroxidase in Spinach Chloroplasts," Plant Cell Physiology, Vol. 22, No. 5, 1981, pp. 867-880.

[18] C. Beauchamp and I. Fridovich, "Superoxide Dismutase Improved Assay and an Assay Applicable to Acrylamide gels," Analytical Biochemistry, Vol. 44, No. 1, 1971, pp. 276-287.

http://dx.doi.org/10.1016/0003-2697(71)90370-8

[19] P. T. Corbishley, J. P. Johnson and R. Williams, "Esterases: Serum Ribonuclease," In: J. Bergmeyer and M. Grabi, Eds., Methods of Enzyme Analysis, Verlag-Chemie, Florida, 1984, pp. 134-148.

[20] R. M. Pugachev, V. A. Matveev and V. V. Skorina, "Influence of Mineral and Hormonal Composition of Nutrient Medium on Prune, Cherry Plum and Sloe Embryos Germination and Growing in Vitro," Sodininkysteir Darzininkyste, Vol. 19, No. 3, 2000, pp. 454-463.

[21] G. Leubner-Metzger, "Brassinosteroids and Gibberellins Promote Tobacco Seed Germination by Different Pathways," Planta, Vol. 213, No. 5, 2001, pp. 758-763. http://dx.doi.org/10.1007/s004250100542

[22] C. M. Steber and P. Mccourt, "A Role for Brassinosteroids in Germination in Arabidopsis," Plant Physiology, Vol. 125, No. 2, 2001, pp. 763-769. http://dx.doi.org/10.1104/pp.125.2.763

[23] J. M. Sasse, R. Smith and I. Hudson, "Effect of 24-Epibrassinolide on Germination of Seeds of Eucalyptus camaldulensis in Saline Conditions," Plant Growth Regulation Society of America, Vol. 22, 1995, pp. 136-141.

[24] S. Anuradha and S. S. R. Rao, "Effect of Brassinosteroids on Salinity Stress Induced Inhibition of Seed Germination and Seedling Growth of Rice (Oryza sativa)," Plant Growth Regulation, Vol. 33, No. 2, 2001, pp. 151-153. http://dx.doi.org/10.1023/A:1017590108484

[25] S. Anuradha and S. S. R. Rao, "The Effect of Brassinosteroids on radish (Raphanussativus) Seedlings Growing under Cadmium Stress," Plant Soil Environment, Vol. 53, 2007, pp. 465-472.

[26] M. P. Gonzalez-Garcia, J. Vilarrssa-Blasi, M. Zhiponova, F. Divol, S. Mora-Garcia, E. Russinova and A. L. CanoDelgado, "Brassinosteroids Control Meristem Size by
Promoting Cell Cycle Progression in Arabidopsis Roots," Development, Vol. 138, No. 5, 2011, pp. 849-859. http://dx.doi.org/10.1242/dev.057331

[27] M. Ashraf, N. A. Akram, R. N. Arteca and M. R. Foolad, "The Physiological, Biochemical and Molecular Roles of Brassinosteroids and Salicylic Acid in Plant Processes and Salt Tolerance," Critical Reviews in Plant Sciences, Vol. 29, No. 3, 2010, pp. 162-190.

http://dx.doi.org/10.1080/07352689.2010.483580

[28] T. K. Macar, O. Turan and Y. Ekmekcd, "Effects of Water Deficit Induced by PEG and $\mathrm{NaCl}$ on Chickpea (Cicer arietinum) Cultivars and Lines at Early Seedling Stages," Gazi University Journal of Science, Vol. 22, No. 1, 2009, pp. 5-14.

[29] D. R. Wu and Y.-J. Zhao, "Effect of Epibrassinolide on the Metabolism of Nucleic Acids in Epicotyls of Mung Bean Seedlings," Actaphysiologica Sinica, Vol. 19, No. 1, 1993, pp. 49-51.

[30] S. M. El_Khallal, T. A. Hathout, A. A. Ashour and A. A. Kerrit, "Brassinolide and Salicylic Acid Induced Growth, Biochemical Activities and Productivity of Maize Plants Grown under Salt Stress," Research Journal of Agricultural and Biological Sciences, Vol. 5, No. 4, 2009, pp. 380-390.

[31] S. Anuradha and S. S. R. Rao, "Application of Brassinosteroids to Rice Seeds (Oryza sativa) Reduced the Impact of Salt Stress on Growth, Prevented Photosynthetic Pigment Loss and Increased Nitrate Reductase Activity," Plant Growth Regulation, Vol. 40, No. 1, 2003, pp. 29-32. http://dx.doi.org/10.1023/A:1023080720374

[32] J. M. Sasse, "Brassinolide-Induced Elongation and Auxin," Physiologia Plantarum, Vol. 80, No. 3, 1990, pp. 401408.

http://dx.doi.org/10.1111/j.1399-3054.1990.tb00059.x

[33] N. Nakajima, Atsubikoshida and S. Toyami, "Effect of Brassinosteroids on Cell Division and Colony Formation of Chinese Cabbage Mesophyll Protoplasts," Japanese Crop Science, Vol. 65, No. 1, 1996, pp. 114-118. http://dx.doi.org/10.1626/jcs.65.114

[34] S. K. Sairam, "Effects of Homobrassinolide Application on Plant Metabolism and Grain Yield under Irrigated and Moisture-Stress Conditions of Two Wheat Varieties," Plant Growth Regulation, Vol. 14, No. 2, 1994, pp. 173-181. http://dx.doi.org/10.1007/BF00025220

[35] S. Anuradha and S. S. R. Rao, "Effect of Brassinosteroids on Salinity Stress Induced Inhibition of Seed Germination and Seedling Growth of Rice (Oryza sativa)," Plant Growth Regulation, Vol. 33, No. 2, 2001, pp. 151-153. http://dx.doi.org/10.1023/A:1017590108484

[36] R. Mittler, "Oxidative Stress Antioxidants and Stress Tolerance," Trends in Plant Science, Vol. 7, No. 9, 2002, pp. 405-410. http://dx.doi.org/10.1016/S1360-1385(02)02312-9

[37] R. G. Alscher, N. Erturk and L. S. Heath, "Role of Superoxide Dismutases (SODs) in Controlling Oxidative Stress in Plants," Journal of Experimental Botany, Vol. 53, No. 372, 2002, pp. 1331-1341. http://dx.doi.org/10.1093/jexbot/53.372.1331 
[38] S. S. Gill and N. Tuteja, "Reactive Oxygen Species and Antioxidant Machinery in Abiotic Stress Tolerance in Crop Plants," Plant Physiology and Biochemistry, Vol. 48, No. 12, 2010, pp. 909-930. http://dx.doi.org/10.1016/i.plaphy.2010.08.016

[39] C. H. Foyer, H. Looez-Delgado, J. F. Dat and I. M. Scott, "Hydrogen Peroxide and Glutathione Associated Mechanisms of Acclimatory Stress Tolerance and Signing," Physiologia Plantarum, Vol. 100, No. 2, 1997, pp. 241-254. http://dx.doi.org/10.1111/j.1399-3054.1997.tb04780.x

[40] C. H. Foyer, P. Descourvieres and K. J. Kunert, "Protection against Oxygen Radicals-An Important DefenceMechanism Studied in Transgenic Plants," Plant, Cell \& Environment, Vol. 17, No. 5, 1994, pp. 507-523. http://dx.doi.org/10.1111/j.1365-3040.1994.tb00146.x

[41] S. Q. Cao, Q. T. Xu, Y. J. Cao, K. Qian, A. Kun, Y. Zhu, B. Z. Hu, H. F. Zhao and B. Kuai, "Loss of Function Mutations in DET2 Gene Lead to an Enhanced Resistance to Oxidative Stress in Arabidopsis," Physiologia Plantarum, Vol. 123, No. 1, 2005, pp. 57-66. http://dx.doi.org/10.1111/j.1399-3054.2004.00432.x

[42] M. Behnamnia, K. H. M. Kalantari and F. Rezanejad, "Exogenous Application of Brassinosteroid Alleviates Drought-Induced Oxidative Stress in Lycopersicon Esculent," General and Applied Plant Physiology, Vol. 35, No. 1-2, 2009, pp. 22-34.

[43] M. C. Zhang, L. S. Duan, Z. X. Zhai, J. M. Li, X. L. Tian, B. M. Wang, Z. P. He and Z. H. Li, "Effects of Plant Growth Regulators on Water Deficit-Induced Yield Loss in Soybean," Proceedings of the 4th International Crop Science Congress, Brisbane, 26 September-1 October

\author{
Abbreviations \\ APX: Ascorbate peroxidase \\ BRs: Brassinosteroids \\ CAT: Catalase \\ EBL: 24-Epibrassinolide \\ EDTA: Ethylenediaminetetraacetic acid \\ HBL: 28-Homobrassinolide \\ MDA: Malondialdehyde
}

2004, p. 132.

[44] A. Michalak, "Phenolic Compounds and Their Antioxidant Activity in Plants Growing under Heavy Metal Stress," Polish Journal of Environmental Studies, Vol. 15, No. 4, 2006, pp. 523-530.

[45] A. Bajguz, "An Enhancing Effect of Exogenous Brassinolide on the Growth and Antioxidant Activity in Chlorella vulgaris Cultures under Heavy Metal Stress," Environmental and Experimental Botany, Vol. 68, No. 2, 2010, pp. 175-179. http://dx.doi.org/10.1016/j.envexpbot.2009.11.003

[46] M. Ashraf and M. R. Foolad, "Roles of Glycine Betaine and Proline in Improving Plant Abiotic Stress Resistance," Environmental and Experimental Botany, Vol. 59, No. 2, 2007, pp. 206-216. http://dx.doi.org/10.1016/j.envexpbot.2005.12.006

[47] M. Farooq, A. Wahid, S. M. A. Basra and I. U. Din, "Improving the Water Relations and Gas Exchange with Brassinosteroids in Rice under Drought Stress," Journal of Agronomy and Crop Science, Vol. 195, No. 4, 2009, pp. 262-269.

[48] B. Ramakrishna and S. S. R. Rao, "24-Epibrassinolide Maintains Elevated Redox State of AsA and GSH in Radish (Raphanus sativus) Seedlings by under Zinc Stress," Acta Physiologia Plantarum, Vol. 35, No. 4, 2013 , pp. 1291-1302.

http://dx.doi.org/10.1007/s11738-012-1168-7
NBT: Nitroblue tetrazolium

PEG: Polyethylene glycol-6000

POD: Peroxidase

SOD: Superoxide dismutase

TBA: Thiobarbituric acid

TCA: Trichloroacetic acid

XTH: sxyloglucan endotransglucosylase/hydrolases 